\title{
CMOS VDIBAs-Based \\ Single-Resistance-Controlled Voltage-Mode Sinusoidal Oscillator
}

\author{
Kanhaiya Lal Pushkar1, Ghanshyam Singh², Rajendra Kumar Goel1 \\ ${ }^{1}$ Department of Electronics and Communication Engineering, Maharaja Agrasen Institute of Technology, New Delhi, India \\ ${ }^{2}$ Department of Electronics and Communication Engineering, HMR Institute of Technology and Management (HMRIT), Delhi, \\ India \\ Email: klpushkar17@gmail.com, ghanshyamsingh_09@rediffmail.com,kumarrajendra2003@gmail.com
}

How to cite this paper: Pushkar, K.L., Singh, G. and Goel, R.K. (2017) CMOS VDIBAs-Based Single-Resistance-Controlled Voltage-Mode Sinusoidal Oscillator. Circuits and Systems, 8, 14-22. http://dx.doi.org/10.4236/cs.2017.81002

Received: December 19, 2016

Accepted: January 22, 2017

Published: January 25, 2017

Copyright @ 2017 by authors and Scientific Research Publishing Inc. This work is licensed under the Creative Commons Attribution International License (CC BY 4.0).

http://creativecommons.org/licenses/by/4.0/

\section{(c) (i) Open Access}

\begin{abstract}
In this communication, a new single-resistance controlled sinusoidal oscillator (SRCO) has been presented. The presented SRCO uses two voltage differencing inverting buffered amplifiers (VDIBAs), one resistor and two capacitors in which one is grounded (GC) and the other one is floating (FC). The proposed structure offers the following advantageous features: 1 ) independent control of oscillation condition (OC) and oscillation frequency $(\mathrm{OF}) ; 2$ ) low passive and active sensitivities and 3) very good frequency stability. The non-ideal effects of the VDIBA on the proposed oscillator have also been investigated. The proposed SRCO has been tested for its robustness using Monte-Carlo simulations. The check of the validity of the presented SRCO has been established by SPICE simulations using $0.18 \mu \mathrm{m}$ TSMC technology.
\end{abstract}

\section{Keywords}

Sinusoidal Oscillator, Voltage Differencing Inverting Buffered Amplifier, Voltage-Mode Circuits, Analog Circuit Design

\section{Introduction}

In analog signal processing and circuit design, realization of active filters and oscillators has become the important research areas. In reference [1] Biolek, Senani, Biolkova, and Kolka have introduced a number of modern analog active building blocks and VDIBA is one of them which is emerging very flexible and versatile active building block for analog signal processing and signal generation. The role played by SRCOs in control systems, signal processing, instrumentation 
and measurement and communication systems is well established in the open literature (see [2] [3] [4] and the references cited therein). Considerable attention has been given by the various researchers in the realization of SRCOs using various active building blocks because of their several merits over conventional op-amp-based SRCOs (see [5]-[16] and the references cited therein). The applications, advantages and usefulness of VDIBA have now been recognized in the realization of the first-order all-pass filter and oscillator [17] [18], and universal biquadratic filters [19] [20]. However, to the best knowledge and belief of the authors, none of the SRCOs using VDIBAs has yet been presented in the literature with independent control of oscillation condition (OC) and oscillation frequency (OF) so far. Therefore, the purpose of this communication is to present a new SRCO using two VDIBAs along with a bare minimum number of three passive components. The proposed structure offers: 1) independent electronic control of oscillation condition; 2) independent control of oscillation frequency through a resistor; 3) low passive and active sensitivities and 4) very good frequency stability. The workability of the proposed SRCO has been confirmed by SPICE simulations using $0.18 \mu \mathrm{m}$ TSMC technology.

\section{New Oscillator Circuit}

The symbolic notation and equivalent model of the VDIBA are given in Figure 1 (a) and Figure 1 (b) respectively [17]. The structure of VDIBA has two voltage inputs of high impedance, a voltage input terminal of low impedance and a current output terminal of high impedance. The ideal terminal equations between port voltages and currents can be expressed as: $I_{+}=0=I_{-}, I_{z}=g_{m}\left(V_{+}-V_{-}\right)$and $\mathrm{V}_{\mathrm{w}-}=-\mathrm{V}_{\mathrm{z}}$, where $\mathrm{g}_{\mathrm{m}}$, represents the transconductance of VDIBA.

The presented single-resistance-controlled sinusoidal oscillator circuit is shown in Figure 2.

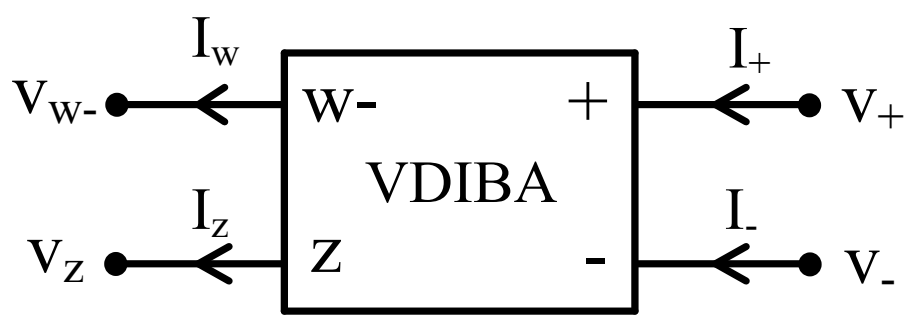

(a)

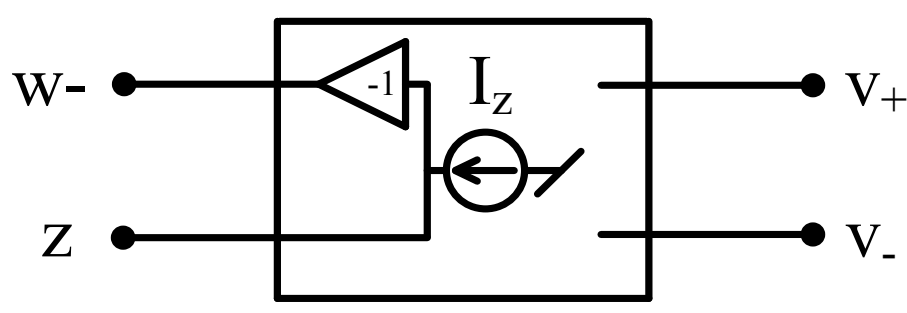

(b)

Figure 1. (a) Symbolic notation; (b) equivalent model of VDIBA. 


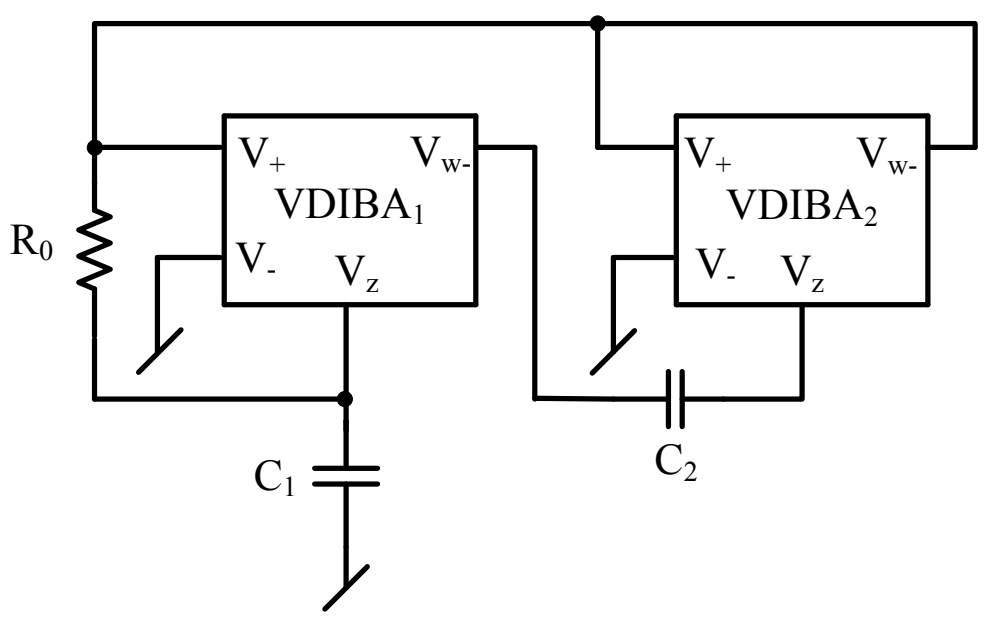

Figure 2. The new SRCO structure.

The characteristic equation (CE) of the proposed SRCO of Figure 2, using a routine circuit analysis can easily be obtained as:

CE:

$$
s^{2} C_{1} C_{2}+s\left\{C_{1} g_{m 2}-C_{2} g_{m 1}\right\}+\frac{g_{m 2}}{R_{0}}=0
$$

From Equation (1), the oscillation condition (OC) and oscillation frequency (OF) can be determined as:

$\mathrm{OC}$ :

$$
\left\{C_{1} g_{m 2}-C_{2} g_{m 1}\right\} \leq 0
$$

and

OF:

$$
\omega_{0}=\sqrt{\frac{g_{m 2}}{C_{1} C_{2} R_{0}}}
$$

From Equations (2) and (3), it is obvious that OF is independently controllable by resistor $\mathrm{R}_{0}$ and $\mathrm{OC}$ is independently controllable electronically by transconductance $g_{m 1}$.

\section{Frequency Stability Analysis of the Presented SRCO}

Frequency stability may be considered to be an important figure of merit of an oscillator. The frequency stability factor is defined as $S^{F}=d \varphi(u) / d u$ [4], where $u=\omega / \omega_{0}$ is the normalized frequency, and $\varphi(u)$ represents the phase function of the open loop transfer function of the oscillator circuit, with $\mathrm{C}_{1}=\mathrm{C} / 2, \mathrm{C}_{2}$ $=\mathrm{C}, \mathrm{R}_{0}=\mathrm{R} / \mathrm{n}$ and $\mathrm{g}_{m 1}=\mathrm{g}_{m 2}=1 / \mathrm{R}, S^{F}$ for the proposed SRCO is found to be

$$
S^{F}=2 \sqrt{2 n}
$$

Thus for larger values of $n$, the presented oscillator circuit enjoys a very good frequency stability.

\section{Non-Ideal Analysis and Sensitivity Performance}

Let $R_{Z}$ and $C_{Z}$ denote the parasitic resistance and parasitic capacitance of the 
Z-terminal of VDIBA. Taking the non-idealities into account, namely, the voltage of W-terminal $V_{W-}=\left(-\beta^{+} V_{Z}\right)$ where $\beta^{+}=1-\varepsilon_{\mathrm{p}}\left(\varepsilon_{\mathrm{p}}<<1\right)$ denotes the voltage tracking error of Z-terminal of VDIBA, the expressions for characteristic equation, $\mathrm{CO}$ and $\mathrm{FO}$ respectively become:

$$
\begin{aligned}
& s^{2}\left\{C_{1} C_{2}+\left(C_{1}+C_{2}+C_{z}\right) C_{z}\right\} \\
& +s\left\{\begin{array}{l}
\left(C_{1}+C_{z}\right)\left(\frac{1}{R_{z}}+\beta^{+} g_{m 2}\right)+\left(C_{2}+C_{z}\right)\left(\frac{1}{R_{0}}+\frac{1}{R_{z}}\right) \\
-\beta^{+2} C_{2}\left(g_{m 1}+\frac{1}{R_{0}}\right)
\end{array}\right\} \\
& +\left(\frac{1}{R_{0}}+\frac{1}{R_{z}}\right)\left(\frac{1}{R_{z}}+\beta^{+} g_{m 2}\right)=0
\end{aligned}
$$

Therefore the expressions for $\mathrm{OC}$ and $\mathrm{OF}$ are given as:

OC:

$$
\left\{\left(C_{1}+C_{z}\right)\left(1+\beta^{+} g_{m 2} R_{z}\right) R_{0}+\left(C_{2}+C_{z}\right)\left(R_{0}+R_{z}\right)-\beta^{+2} R_{z} C_{2}\left(1+g_{m 1} R_{0}\right)\right\} \leq 0(6)
$$

OF:

$$
\omega_{0}=\sqrt{\frac{R_{0}+R_{z}+\beta^{+} g_{m 2} R_{z}\left(R_{0}+R_{z}\right)}{R_{0} R_{z}^{2}\left\{C_{z}\left(C_{1}+C_{2}+C_{z}\right)+C_{1} C_{2}\right\}}}
$$

Therefore the active and passive sensitivities can be obtained as:

$$
\begin{aligned}
& S_{C_{1}}^{\omega_{0}}=-\frac{1}{2} \frac{1}{1+\frac{C_{z}^{2}+C_{2} C_{Z}}{C_{1}\left(C_{2}+C_{Z}\right)}}, S_{C_{2}}^{\omega_{0}}=-\frac{1}{2} \frac{1}{1+\frac{C_{z}^{2}+C_{1} C_{Z}}{C_{2}\left(C_{1}+C_{Z}\right)}}, S_{R_{0}}^{\omega_{0}}=-\frac{1}{2}\left\{\frac{R_{z}}{R_{0}+R_{z}}\right\}(8) \\
& S_{C_{Z}}^{\omega_{0}}=-\frac{1}{2} \frac{1}{1+\frac{C_{1} C_{2}-C_{z}^{2}}{C_{z}\left(C_{1}+C_{2}+2 C_{Z}\right)}}, S_{R_{z}}^{\omega_{0}}=-\frac{1}{2}\left\{\frac{2 R_{0}+R_{z}\left(1+\beta^{+} g_{m 2} R_{0}\right)}{R_{0}+R_{z}+\beta^{+} g_{m 2} R_{z}\left(R_{0}+R_{z}\right)}\right\} \text { (9) } \\
& S_{\beta^{+}}^{\omega_{0}}=\frac{1}{2} \frac{1}{1+\frac{1}{\beta^{+} g_{m 2} R_{z}}}=S_{g_{m 2}}^{\omega_{0}}
\end{aligned}
$$

Ideally, the various sensitivities of OF with respect to passive elements $C_{z}, R_{z}$, $\mathrm{C}_{1}$, and $\mathrm{C}_{2}$ are found to be

$$
S_{C_{z}}^{\omega_{0}}=S_{R_{z}}^{\omega_{0}}=0, S_{C_{1}}^{\omega_{0}}=S_{C_{2}}^{\omega_{0}}=-\frac{1}{2}
$$

For the typical values of $\mathrm{C}_{\mathrm{z}}=0.81 \mathrm{pF}, \mathrm{R}_{\mathrm{z}}=53 \mathrm{k} \Omega, \beta^{+}=1$ along with $\mathrm{C}_{1}=0.5 \mathrm{nF}$, $\mathrm{C}_{2}=1.0 \mathrm{nF}, \mathrm{R}_{0}=950 \Omega$, the various sensitivities are found to be $S_{C_{1}}^{\omega_{0}}=-0.391$, $S_{C_{2}}^{\omega_{0}}=-0.276, S_{C_{Z}}^{\omega_{0}}=-0.533, S_{R_{0}}^{\omega_{0}}=-0.491, S_{\beta^{+}}^{\omega_{0}}=0.477=S_{g_{m}}^{\omega_{0}}$, $S_{R_{Z}}^{\omega_{0}}=-0.0241$ which are all low.

Figure 3 shows the CMOS implementation of the VDIBA used, which was biased with $\mathrm{V}_{\mathrm{DD}}=0.9 \mathrm{~V}$ D.C. $=-\mathrm{V}_{\mathrm{SS}}$ and $\mathrm{I}_{\mathrm{b}}$ was taken $100 \mu \mathrm{A}$.

\section{Simulation Results}

To confirm theoretical analysis, the proposed SRCO was simulated using CMOS 
VDIBA (as shown in Figure 3 ). The passive components were used as $C_{1}=0.5$ $\mathrm{nF}, \mathrm{C}_{2}=1.0 \mathrm{nF}, \mathrm{R}_{0}=950 \Omega$. The transconductance of VDIBA was controlled by bias current $\mathrm{I}_{\mathrm{b}}$. SPICE generated output waveforms indicating transient and steady state responses are shown in Figure 4(a) and Figure 4(b) respectively.

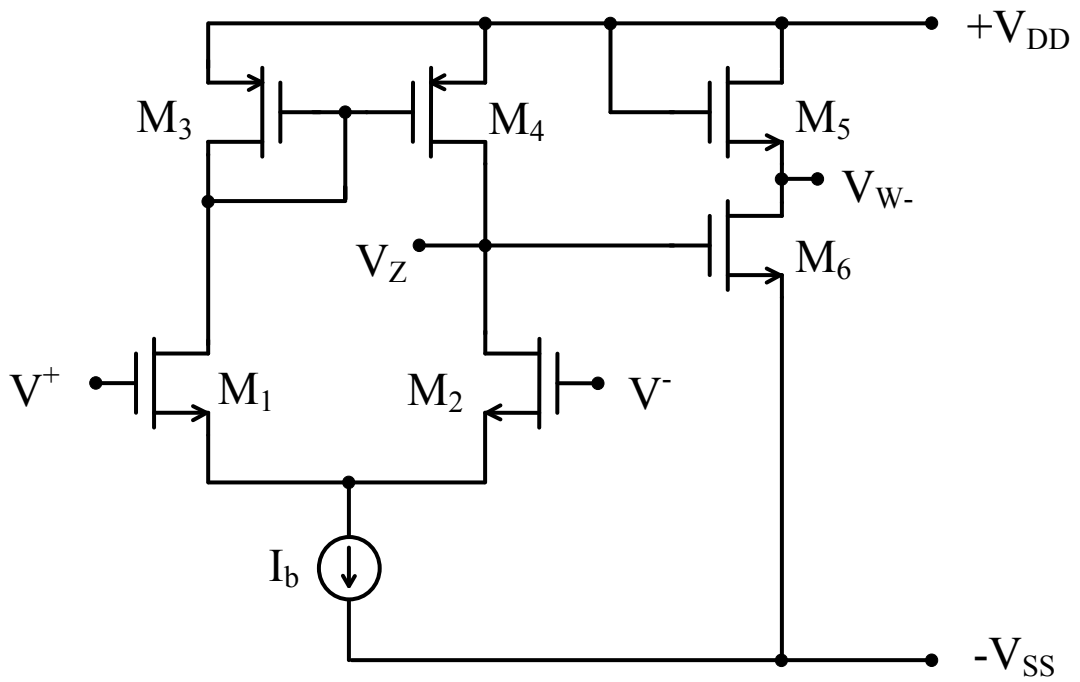

Figure 3. Implementation of CMOS VDIBA [17].

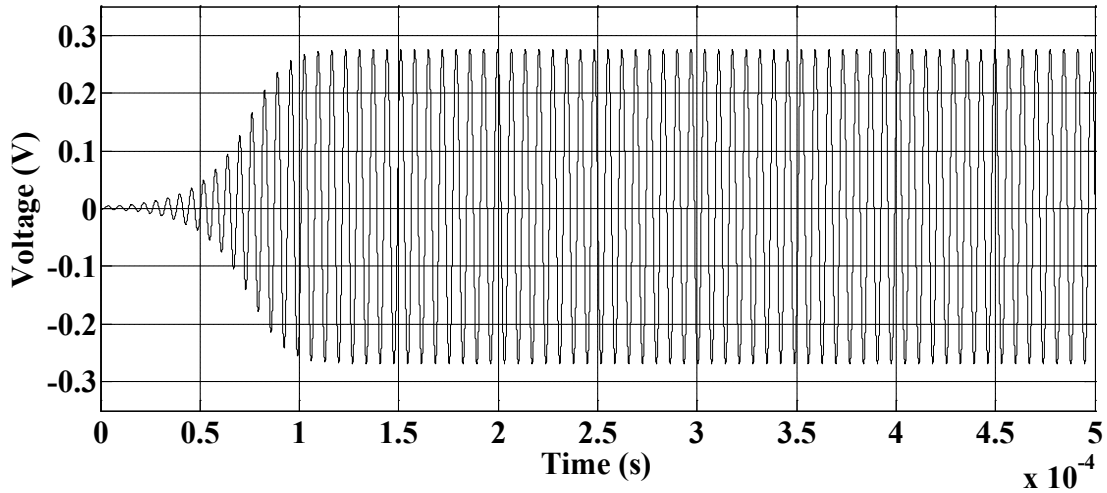

(a)

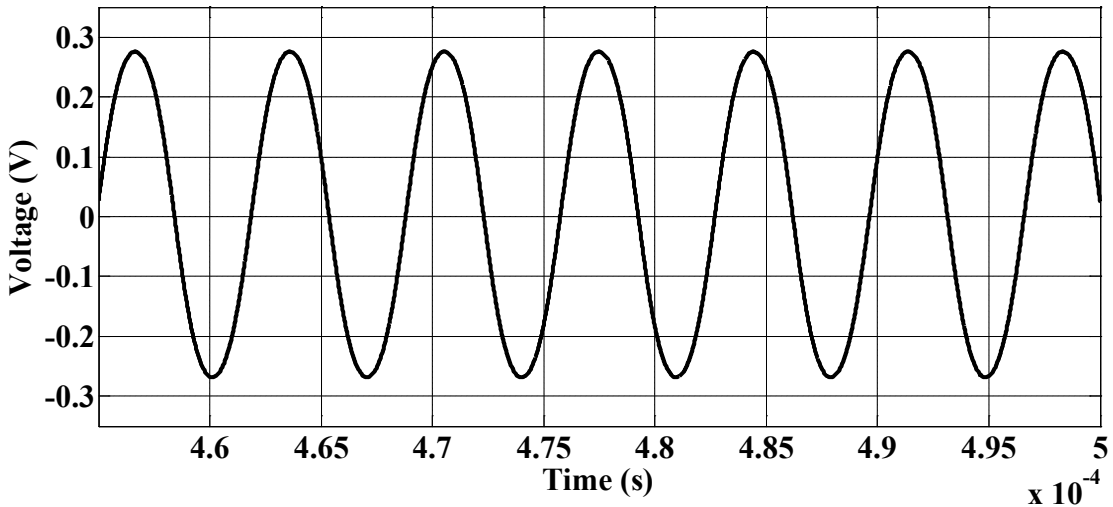

(b)

Figure 4. (a) Transient output waveform; (b) Steady state response of the output. 
These results, thus, confirm the validity of the proposed configuration. Figure 5 shows the output spectrum, where the total harmonic distortion (THD) is found to be $1.996 \%$. Figure 6 shows the variation of frequency with resistance $R_{0}$. A comparison with other previously known SRCOs using different active building blocks has been given in Table 1 .

The implementation of CMOS VDIBA employing $0.18 \mu \mathrm{m}$ TSMC technology was used from [17] and the device parameters were taken from [21]. The aspect ratios of various MOSFETs used in CMOS VDIBA of Figure 7 were taken from reference [18].

From Equations (8) - (10), this is obvious that the values of various sensitivities of passive and active components are less than half.

\section{Conclusion}

This work presents VDIBAs-based SRCO which employs minimum number of passive elements (namely, one resistor, two capacitors) and offers independent control of OF through the resistor $\mathrm{R}_{0}$ and OC through the transconductance $g_{m 1}$ (thus the circuit enjoys the electronic control of $\mathrm{OC}$ ), low passive and active sen-

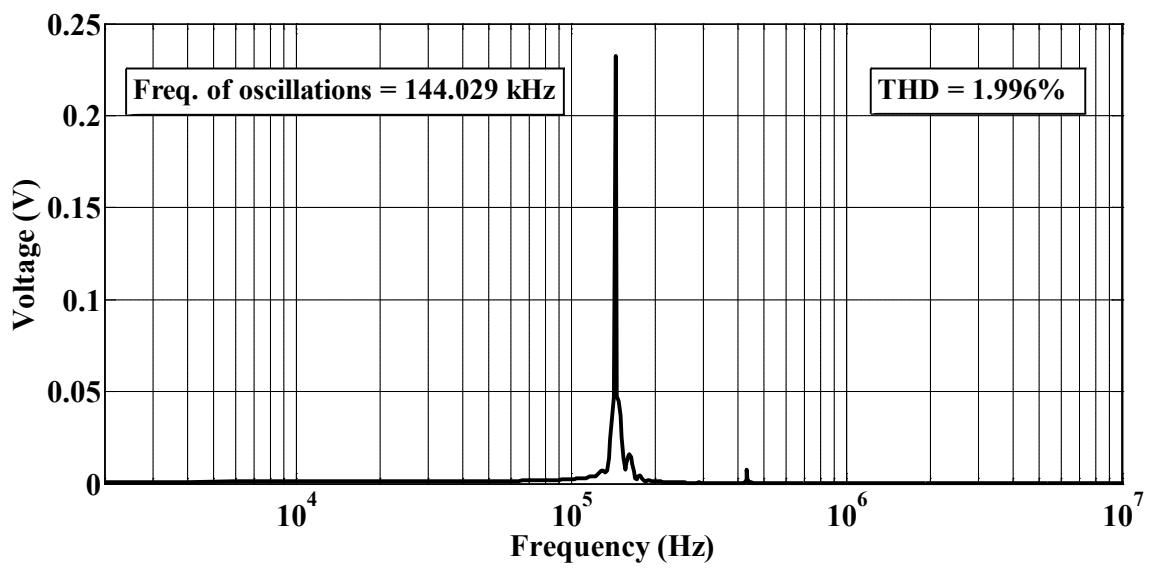

Figure 5. Simulation result of the output spectrum.

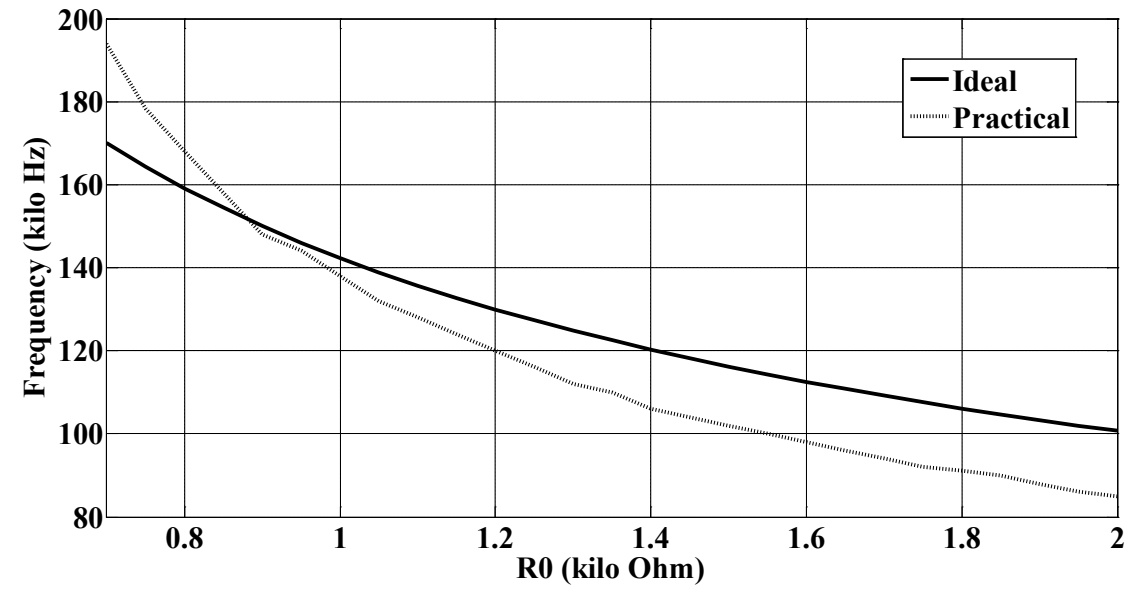

Figure 6. Variation of frequency with R0 of the proposed SRCO. 
Table 1. A comparison with other previously known SRCOs using different active building blocks.

\begin{tabular}{|c|c|c|c|c|c|c|}
\hline Reference & $\begin{array}{c}\text { Active } \\
\text { Element }\end{array}$ & $\begin{array}{l}\text { Number of } \\
\text { Active } \\
\text { Element(s) }\end{array}$ & $\begin{array}{l}\text { Number } \\
\text { of GC }\end{array}$ & $\begin{array}{c}\text { Number } \\
\text { of FC }\end{array}$ & $\begin{array}{c}\text { Number. of } \\
\text { Resistors }\end{array}$ & $\begin{array}{l}\text { Whether OC } \\
\text { and OF are } \\
\text { Independently } \\
\text { Controllable? }\end{array}$ \\
\hline [5] & CFOA & 1 & 1 & 1 & 3 & YES \\
\hline [6] & CC-II (+) & 1 & 1 & 1 & 3 & YES \\
\hline [7] & $\begin{array}{c}\text { CC-II (-) + } \\
\text { Buffer }\end{array}$ & 2 & 2 & 0 & 3 & YES \\
\hline [8] & PFTFN & 1 & 1 & 1 & 3 & YES \\
\hline [9] & PNFTN & 1 & 2 & 0 & 4 & NO \\
\hline [10] & $\begin{array}{c}\text { NFTFN + } \\
\text { Buffer }\end{array}$ & 2 & 2 & 0 & 3 & YES \\
\hline [11] & DVCCC & 1 & 2 & 0 & 3 & YES \\
\hline [12] & DVCCC & 1 & 2 & 0 & $3 / 2$ & YES \\
\hline [13] & CDBA & 1 & $\begin{array}{l}1 \text { virtually } \\
\text { grounded) }\end{array}$ & 1 & 3 & $\begin{array}{c}\text { YES( only in } \\
\text { second topology of } \\
\text { Table 1) }\end{array}$ \\
\hline [14] & OTRA & 1 & $\begin{array}{l}1 \text { virtually } \\
\text { grounded) }\end{array}$ & 1 & 3 & NO \\
\hline [15] & CDTA & 1 & 1 & 1 & 2 & YES \\
\hline [16] & VD-DIBA & 2 & 2 & 0 & 1 & YES \\
\hline [17] & VDIBA & 2 & 1 & 1 & 1 & $\mathrm{NO}$ \\
\hline [22] & VD-DIBA & 1 & 2 & 0 & 2 & YES \\
\hline [23] & VD-DIBA & 1 & 1 & 1 & 2 & YES \\
\hline Proposed & VDIBA & 2 & 1 & 1 & 1 & YES \\
\hline
\end{tabular}
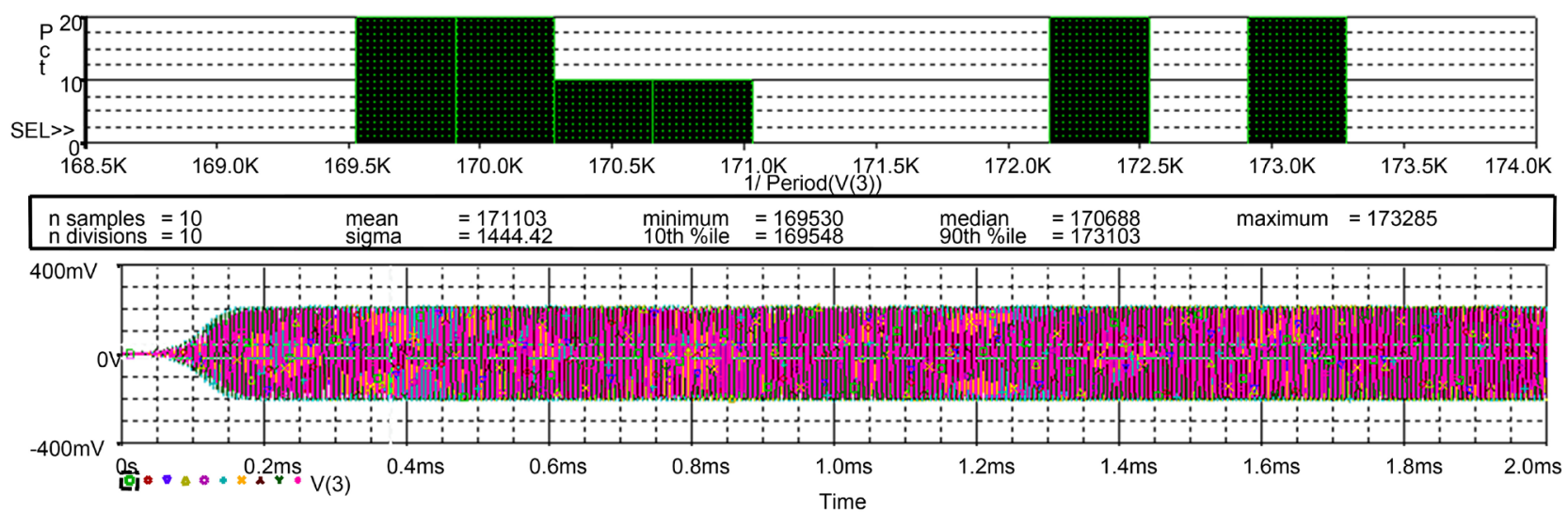

Figure 7. Monte-Carlo analysis of the SRCO.

sitivities and a very good frequency stability. This communication, therefore, added a new application circuit to the existing repertoire of VDIBAs-based application circuits.

\section{Acknowledgements}

The authors gratefully acknowledge Prof. Dr. D. R. Bhaskar, Professor, Depart- 
ment of Electronics and Communication Engineering, Delhi Technological University, Shahbad Daulatpur, Main Bawana Road, Delhi-110042, India, useful suggestions/discussions.

\section{References}

[1] Biolek, D., Senani, R., Biolkova, V. and Kolka, Z. (2008) Active Elements for Analog Signal Processing; Classification, Review and New Proposals. Radioengineering, 17, 15-32.

[2] Senani, R. (1985) New Types of Sine Wave Oscillators. IEEE Transactions on Instrumentation and Measurement (USA), 34, 461-463.

https://doi.org/10.1109/TIM.1985.4315370

[3] Senani, R. and Bhaskar, D.R. (1991) Single-Op-Amp Sinusoidal Oscillators Suitable for Generation of Very Low Frequencies. IEEE Transactions on Instrumentation and Measurement (USA), 40, 777-779. https://doi.org/10.1109/19.85353

[4] Bhaskar, D.R. and Senani, R. (2006) New CFOA-Based Single-Element-Controlled Sinusoidal Oscillators. IEEE Transactions on Instrumentation and Measurement (USA), 55, 2014-2021. https://doi.org/10.1109/TIM.2006.884139

[5] Singh, V.K., Sharma, R.K., Singh, A.K., Bhaskar D.R. and Senani, R. (2005) Two New Canonic Single-CFOA Oscillators with Single Resistor Controls. IEEE Transactions on Circuits and Systems II: Express Brief (USA), 52, 860-864. https://doi.org/10.1109/TCSII.2005.853964

[6] Celma, S., Martinez, P.A. and Carlosena, A. (1992) Minimal Realisation for Single Resistor Controlled Sinusoidal Oscillator Using Single CCII. Electronics Letters, 28, 443-444. https://doi.org/10.1049/el:19920279

[7] Bhaskar, D.R. and Senani, R. (1993) New Current-Conveyor-Based Single-Resistance-Controlled/Voltage-Controlled Oscillator Employing Grounded Capacitors. Electronics Letters, IEE (UK), 29, 612-614. https://doi.org/10.1049/el:19930410

[8] Lee, C.T. and Wang, H.Y. (2001) Minimum Realization for FTFN-Based SRCO. Electronics Letters, IEE (UK), 37, 1207-1208. https://doi.org/10.1049/el:20010856

[9] Bhaskar, D.R. (2002) Grounded-Capacitor SRCO Using Only One PFTFN. Electronics Letters, IEE (UK), 38, 1156-1157. https://doi.org/10.1049/el:20020839

[10] Bhaskar, D.R. (1999) Single Resistance Controlled Sinusoidal Oscillator Using Single FTFN. Electronics Letters, IEE (UK), 35, 190-191.

https://doi.org/10.1049/el:19990161

[11] Gupta, S.S. and Senani, R. (2000) Grounded-Capacitor Current-Mode SRCO: Novel Application of DVCCC. Electronics Letters, 36, 195-196.

https://doi.org/10.1049/el:20000240

[12] Aggarawal, V., Kilinc, S. and Cam, U. (2006) Minimum Component SRCO and VFO Using a Single DVCCC. Analog Integrated Circuits and Signal Processing, 49, 181-185. https://doi.org/10.1007/s10470-006-9364-2

[13] Ozcan, S., Toker, A., Acar, C., Kuntman, H. and Cicekoglu, O. (2000) Single Resistance-Controlled Sinusoidal Oscillators Employing Current Differencing Buffered Amplifier. Microelectronics Journal, 31, 169-174. https://doi.org/10.1016/S0026-2692(99)00113-5

[14] Cam, U. (2002) A Novel Single-Resistance-Controlled Sinusoidal Oscillator Employing Single Operational Transresistance Amplifier. Analog Integrated Circuits and Signal Processing, 32, 183-186. https://doi.org/10.1023/A:1019586328253

[15] Prasad, D.D.R., Bhaskar, R. and Singh, A.K. (2008) Realisation of Single-Resistance- 
Controlled Sinusoidal Oscillator: A New Application of the CDTA. WSEAS Trans. Electronic, 6, 257-259.

[16] Prasad, D., Bhaskar, D.R. and Pushkar, K.L. (2013) Electronically Controllable Sinusoidal Oscillator Employing CMOS VD-DIBAs. ISRN Electronics, 2013, Article ID: 823630. https://doi.org/10.1155/2013/823630

[17] Herencsar, N., Minaei, S., Koton, J., Yuce, E. and Vrba, K. (2013) New Resistorless and Electronically Tunable Realization of Dual-Output VM All-Pass Filter Using VDIBA. Analog Integrated Circuits and Signal Processing, 74, 141-154. https://doi.org/10.1007/s10470-012-9936-2

[18] Herencsar, N., Koton, J., Minaei, S., Yuce, E. and Vrba, K. (2011) Novel Resistorless Dual-Output VM All-Pass Filter Employing VDIBA. ELECO 20117 th International Conference on Electrical and Electronics Engineering, Bursa, 1-4 December 2011, 72-74.

[19] Pushkar, K.L., Bhaskar, D.R. and Prasad, D. (2014) Voltage-Mode New Universal Biquad Filter Configuration Using a Single VDIBA. Circuits, System and Signal Processing, 33, 275-285. https://doi.org/10.1007/s00034-013-9625-0

[20] Herencsar, N., Cicekoglu, O., Sotner, R., Koton, J. and Vrba, K. (2013) New Resistorless Tunable Voltage-Mode Universal Filter Using Single VDIBA. Analog Integrated Circuit and Signal Processing-Springer, 76, 251-260. https://doi.org/10.1007/s10470-013-0090-2

[21] Minaei, S. and Yuce, E. (2010) Novel Voltage-Mode All-Pass Filter Based on Using DVCCs. Circuits, System and Signal Processing, 29, 391-402.

https://doi.org/10.1007/s00034-010-9150-3

[22] Pushkar, K.L., Bhaskar, D.R. and Prasad, D. (2013) Single-Resistance-Controlled Sinusoidal Oscillator Using Single VD-DIBA. Active and Passive Electronic Components, 2013, Article ID: 971936. https://doi.org/10.1155/2013/971936

[23] Pushkar, K.L., Goel, R.K., Gupta, K., Vivek, P. and Ashraf, J. (2016) New VDDIBA-Based Single-Resistance-Controlled Sinusoidal Oscillator. Circuits and Systems, 7, 4145-4153. https://doi.org/10.4236/cs.2016.713341

Submit or recommend next manuscript to SCIRP and we will provide best service for you:

Accepting pre-submission inquiries through Email, Facebook, LinkedIn, Twitter, etc. A wide selection of journals (inclusive of 9 subjects, more than 200 journals)

Providing 24-hour high-quality service

User-friendly online submission system

Fair and swift peer-review system

Efficient typesetting and proofreading procedure

Display of the result of downloads and visits, as well as the number of cited articles

Maximum dissemination of your research work

Submit your manuscript at: http://papersubmission.scirp.org/

Orcontactcs@scirp.org 